\title{
A STUDY OF FINANCIAL LITERACY AND ITS DETERMINANTS: EVIDENCE FROM INDIA
}

\author{
Kapil Choudhary ${ }^{*} \&$ Samriti Kamboj
}

\begin{abstract}
Financial Literacy has become a priority area across the world in recent years. In a complex and globalized marketplace, a myriad of products is offered in the financial market, and the accessibility of products has also increased. This has made it imperative for individuals to be well equipped with the necessary financial knowledge and awareness to use their financial resources in an optimum way. The study examines the financial literacy of the people by using a questionnaire developed by the Organisation for Economic Cooperation and Development (OECD). The data were collected from 500 respondents from the state of Haryana. The findings reveal that only one-third of the total sample exhibit higher financial literacy. Although the majority of the people possess basic financial knowledge and exhibit positive financial behaviour, 57 per cent of the respondents lack a positive financial attitude. This suggests the need for the introduction of initiatives on the part of policymakers, which may be beneficial in changing the attitudes of the respondents. However, analysis of the socio-demographics suggests that certain factors may prevent persons from being more financially literate. In particular, low levels of income, income instability, and low age are associated with lower levels of financial literacy. The present study offers the first ever comprehensive insight into the financial literacy of the Haryana region.
\end{abstract}

Keywords: Financial Attitude, Financial Behaviour, Financial Knowledge, Financial Literacy, Socio-demographic Factors

JEL Classification: D14, I22

\section{Introduction}

In today's financial world, the importance of financial education is globally acknowledged as being a key component of the financial well-being of an individual as well as the financial stability of a country. Nowadays, consumers are entering a risky marketplace where they are confronted with a wide array of financial products and services. The baffling choices in these products and the clever advertising often mystify consumers and prevent them understanding the fine print of the complex information and the downside risk associated therein. The situation becomes more complicated due to technological innovations that

\footnotetext{
* Corresponding Author: Kapil Choudhary is an Assistant Professor at the Department of Commerce, Chaudhary Devi Lal University, Sirsa-Haryana, India. Email: kapilcdlu@gmail.com Samriti Kamboj is an Assistant Professor (Commerce), Ch. Mani Ram Jhorar Govt. College, Mithi Sureran, Ellenabad (Sirsa) Haryana, India. Email: ssamritikamboj@gmail.com
}

The corresponding author is thankful to University Grant Commission, New Delhi, India, for providing financial assistance to carry out this research work. 
have resulted in an explosion of new products. This increases the responsibility and risk of households in making financial decisions. The need arises to equip financial consumers with basic financial knowledge and skills to enable them to navigate the complex range of products and services and select those that best suit their needs and resources.

The increase in market complexity, exposure to advanced financial technology like mobile and online payments, the increase in the financial responsibility of individuals due to the shift from defined pension plans to contributory plans, and the concern for retirement planning and healthcare needs make it essential to understand the financial concepts and make judicious decisions regarding financial transactions. Financial literacy enhances the knowledge and builds confidence among households to manage their financial affairs towards a secure financial future. Research shows that financial literacy has a positive spill over effect on the economy. People who can accurately undertake simple calculation and are knowledgeable about inflation and risk diversification tend to plan more for their retirement (Lusardi \& Mitchell, 2009; Hastings \& Mitchell, 2011; Lusardi \& Mitchell, 2011). The findings of research conducted by Klapper and Panos (2011) reveal that financial literacy is positively and significantly associated with retirement planning. Financial unawareness and the resultant behaviour lead to negative financial outcomes that have an adverse effect on an individual's financial well-being. A lack of knowledge of key economic concepts and skills causes individuals to enter into suboptimal financial decisions (Hastings \& Mitchell, 2011). People with little financial knowledge hold wrong opinions about financial concepts, and, as a result, make erroneous financial decisions (Chen \& Volpe, 1998).They participate less in the stock market (Rooij, Lusardi, \& Alessie, 2007), have poor borrowing behaviour, accumulate less wealth with no optimal plans for retirement (Lusardi, 2008; Lusardi \& Mitchell, 2008; 2009); and are more likely to enter into high-cost transactions (Lusardi \& Tufano, 2009) relative to their financially literate counterparts. The protection of financial consumers also demands financial literacy as it enables people to be aware of the risks inherent in financial products and control their greed for high returns. The recent global financial crisis highlighted the impact of financial illiteracy on the financial stability of the Western world. "The epicentre of the crisis was the Subprime Mortgage Sector in the United States and insufficient levels of financial literacy were among the major aggravating factors" (OECD Deputy Secretary, 2010, p.1). The individuals did not possess the financial skills and knowledge essential to make a competent evaluation, which resulted in the subsequent bust in the financial market (Volpe \& Mumaw, 2010). The gigantic destruction illustrates the importance of understanding the financial basics and the need for a sound regulatory and consumer protection framework.

"Lack of literacy in general and financial literacy in particular, are the main hurdles in expanding the coverage of financial services to the poorer segments of the society" (K.C. Chakrabarty, Former Deputy Governor, RBI, 2009). Financial literacy is a complement to financial inclusion, particularly in 
emerging economies where a sizeable proportion of people are outside the ambit of the financial system. In order to remove financial untouchability, there is a wider expansion of bank branches to provide basic banking services to the people in India. However, the accounts opened under various government schemes are characterized by fewer transactions of small value. This exhibits that people have the accessibility, but they lack the knowledge and understanding about the 'use' and 'benefits' of the products and services offered by the financial institutions. In India, most people are risk-averse, and, for centuries, consider investing in gold and land as the safest saving products. These funds represent a vast pool of financial resources and a large capital infusion in the economy if invested in productive financial products and services. Therefore, there is great need for financial literacy in India.

The way towards a financially literate India is also very challenging due to the large unbanked population, low literacy levels, poverty, regional languages, varied cultures, and the wide disparity in socio-economic development. The wide diversity of the culture, beliefs, religion, and customs in different states direct the behaviour of people and also frame their attitude. Thus, in such circumstances, this kind of study is the need of the hour to measure the financial literacy of people. This study is an effort to bring forth the empirical evidence regarding the level of financial literacy of the people of Haryana. An attempt has been made to examine the impact of the socio-demographic factors on the financial literacy of people. The findings could be helpful in formulating tailormade financial education programmes, and appropriate study material can be designed with due consideration of the educational background, residence, and socio-economic status of these population sub-groups.

Most of the widely used definitions of financial literacy point to the ability of individuals to acquire, understand, and evaluate information in order to make precise decisions to secure a better financial future for them. The literature pertaining to the issue has identified five domains of personal finance - making ends meet, keeping track, choosing products, planning ahead, staying informed, and getting help. All these domains consist of financial knowledge, financial attitudes, and financial practices that together makeup the concept of financial literacy. These domains are efficiently reflected by the OECD definition of financial literacy, which defines it as "A combination of awareness, knowledge, and skill, attitude andbehaviour necessary to make sound financial decisions and ultimately achieve individual financial wellbeing" (Atkinson \& Messy, 2012). The definition was endorsed by the G20 leaders in 2012. The study adopts the questionnaire developed by the OECD that tends to examine the overall financial literacy of the people by measuring the three most important dimensions of financial literacy - financial knowledge, financial attitude, and financial behaviour. These individual dimensions potentially deliver vital insights beyond those provided by financial literacy alone. Furthermore, there is no internationally acknowledged survey instrument that captures this level of detail since it has been used for surveys in 13 countries. 
Financial literacy has become a matter of deep concern all over the world. The problem of financial illiteracy is not confined to developing or underdeveloped nations but rather is pervasive throughout. In an international project measuring financial literacy across eight countries, Lusardi and Mitchell (2011) found low financial literacy even in well-developed financial markets. The survey instrument was designed to include three questions covering the aspects of interest compounding, inflation, and risk diversification. Moreover, variations in the financial literacy scores were found among the sub-groups of the population. The age pattern for financial literacy depicted a ' $U$ ' shaped curve demonstrating lower financial literacy for youth and the older groups. Women and less educated were less financially literate. Significant differences were traced in the financial literacy of people on the basis of urbanity, race, region, and religion. In addition, the people who were knowledgeable about the key financial concepts were more likely to plan for their retirement.

Another OECD International Network on Financial Education study was conducted by Atkinson and Messy (2012) in 14 countries across 4 continents. Financial literacy was measured on the basis of three aspects of financial literacy; namely, financial knowledge, financial behaviour, and financial attitude. The results highlighted a lack of financial knowledge among a large proportion of the population in all the countries surveyed. Less awareness was found concerning the aspects of diversification and compound interest. Women had a lower level of financial knowledge than men in most of the countries. Apositive relationship existed between income and financial literacy, and a high level of financial knowledge, positive behaviour and attitude were depicted by higher educated people. The analysis also revealed that people with higher knowledge were more likely to exhibit positive financial behaviour. A similar relationship emerged for financial attitude and financial behaviour.

A study by Lusardi (2008) demonstrated the lack of financial literacy among the US population. However, low levels of financial literacy were concentrated among people who were less educated, women, AfricanAmericans, and Hispanics. The findings also showed that unawareness of financial concepts resulted in a lack of retirement planning, no participation in the stock market, and poor borrowing behaviour.

A telephonic financial literacy survey was conducted in the United States by Harris Interactive (2012) on behalf of the National Foundation for Credit Counselling and the Network Branded Prepaid Card Association among 1,007 adults. The findings revealed that 56 per cent of US adults did not have a budget and did not keep close track of their expenditures; 33 per cent did not pay all of their bills on time, and credit card debt was carried by two in five Americans. During the financial problem, 27 per cent preferred their friends and family for assistance as their first preference. The results indicated a lack of positive financial behaviour among a large proportion of Americans.

In order to examine the relationship between financial literacy and retirement planning in Russia, Klapper and Panos (2011) used a questionnaire 
consisting of questions on the interest rate, inflation, and risk diversification. The findings reported low levels of financial knowledge among the majority of the respondents, with36.3 per cent of the respondents of the sample understanding the concept of compound interest, and 50 per centbeing knowledgeable about inflation. Only 12.8 per cent answered a question on risk diversification in asset investments. The results explained that financial literacy positively affected the retirement planning of the respondents. Further, high financial literacy was found among the younger and higher educated respondents. The retired and selfemployed individuals possessed a low level of financial literacy. Rural people were less financially literate than respondents living in urban areas and were less reliant on private pension schemes.

The research report conducted by the Australian Securities and Investments Commission (2011), exhibited the financial literacy status of Australians. The findings stated that socio-demographic characteristics like age, gender, education, and income had a bearing on the knowledge, attitude, beliefs, confidence levels, and interest of the people about monetary concepts. The financial literacy level of Australians was quite reasonable. However, the confidence and knowledge of the people declined with an increase in the complexity and unfamiliarity of the financial topic. People were found to be knowledgeable and confident about routine financial concepts but felt uncomfortable with complex concepts, e.g., retirement savings and investments.

A Master Card Financial Literacy Survey was conducted between July 2014 and August 2014 on 8,087 respondents aged 18-64 in 16 countries across the Asia Pacific Region. The survey instrument comprised questions covering three major components: basic money management, financial planning and investment. As light decline was observed in the financial planning knowhow of the respondents in comparison with the results of the last survey carried out in 2013. On the Investment component, the Asia Pacific Region showed the weakest progress for the three components of the Financial Literacy Index. In addition, developed markets took the lead in financial knowhow, with Taiwan, New Zealand, and Hong Kong in the top positions. Consumers who worked or belonged to a high-income class possessed superior levels of financial literacy than others.

The study conducted by Yoshino, Morgan, and Wignaraja (2015) on behalf of the Asian Development Bank Institute found low financial literacy scores for Asian countries. Highlighting the substantial effects of financial literacy on the economic development of a country, the researchers emphasized the need for more concerted policy efforts for financial literacy at the national level.

The statistics regarding financial literacy are quite shocking in India. The 2012 edition of Visa Global Financial Literacy Barometer demonstrated that India was lagging behind the global standard and secured the 23rd slot in the overall ranking. Another financial literacy survey was conducted by Agarwalla, Barua, Jacob, and Varma (2012) in India on a sample of 3,000 people to examine the financial literacy of students, young employees, and retired people. 
Financial literacy was measured on the basis of three dimensions, i.e., financial knowledge, financial behaviour, and financial attitude. The study highlighted less financial literacy among the respondents, which was due to poor financial knowledge among Indians. The results showed that less than a quarter of the respondents were categorised among the high financial knowledge class. Moreover, a low level of financial knowledge among women was revealed by the study. However, a positive attitude towards savings and consumption, as well as positive financial behaviour was depicted by Indians. Education and income were found to have a positive impact on the financial literacy level of the people.

The above review of the literature exhibits widespread financial illiteracy across the world irrespective of the level of financial development of a country. Most of the studies found noticeable variations in the financial literacy of the individuals on the basis of socio-demographic variables. Thus, certain variables - age, gender, education, income, residence, and occupation - emerge as determinants of financial literacy.

In the financial literacy literature, there are only a few studies in the Indian context. It is a newly-born issue for research in India. In order to re-examine and yield further improvements in the results, the present study was conducted to bring forth the empirical evidence regarding the level of financial literacy and possible causes of financial illiteracy of the respondents of this region. A study of the factors affecting financial literacy helps in identifying the vulnerable target groups, such as women, senior citizens, the poor, and unemployed youth. From the viewpoint of academics, it is vital to understand and conduct research in the field of behavioural finance. A study of this type could be helpful for the policymakers in formulating policies to improve the financial literacy levels of the people of Haryana. The data were collected on the basis of various sociodemographic factors, and tailor-made strategies could be framed for uplifting the particular sub-groups of the population.

\section{Motivations and Objectives of the Study}

Historically, India is country of wide diversity in terms of the cultural and socioeconomic contexts, which make the evolution and measurement of financial literacy a challenging task. Hence, comprehensive research on the financial literacy and its components viz. financial knowledge, attitude, andbehaviour could provide much deeper insights for effective policy formulation. Awareness/training programmes and advertisement campaigns, etc., may be conducted for respondents on the components of financial literacy for which their score is low. The results of the present study may also be beneficial in enhancing the understating of financial literacy, and, consequently, increase the chances of making an informed and effective decision when selecting a financial product.

Primarily, the present study is intended to assess the level of financial literacy of the respondents from Haryana. Further, it aims to depict the relationship between financial literacy and various demographic factors - 
gender, domicile, marital status, work situation, age group, educational level, household income, and income stability.

\section{Research Methodology}

A structured questionnaire developed by the OECD International Network on Financial Education (INFE) was used to capture the financial literacy level of the people. Formal approval was received from the OECD for the use of the questionnaire. However, modifications were made to the questionnaire for the ease and convenience of the respondents by making it bilingual (English and Hindi). All the information was collected by personal interviews using the questions included in the questionnaire. The questionnaire used in the survey covers the most important dimensions of financial literacy: financial knowledge, financial behaviour, and financial attitude. The study attempts to analyse the financial literacy of the respondents on the basis of the socio-demographic variables.

\subsection{Sampling and data collection}

The research was conducted to assess the financial literacy level of the people of Haryana. For this purpose, the sampling frame comprised respondents aged 20 years or above from five districts of Haryana -Sirsa, Fatehabad, Hisar, Bhiwani, and Rohtak. These five districts represent most of the cultural and socioeconomic features of the small state of Haryana. Furthermore, respondents hailing from these districts are well-diversified in terms of occupation, income as well as education level. From the sampling frame, the study uses a sample of 500 respondents. All the respondents were contacted directly by visits in the field. Out of the total sample respondents, 20 per cent were randomly selected from each of the five districts. The data collected were gender, domicile, marital status, work situation, age group, educational level, and household income.

\subsection{Survey Sample Profile}

The demographic characteristics of the surveyed sample are:

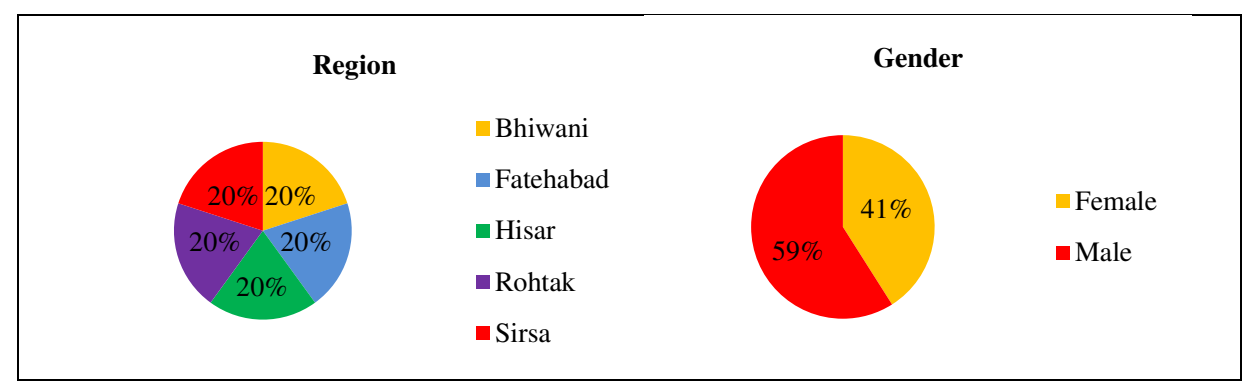

Figure 1. Sample demographic characteristics 


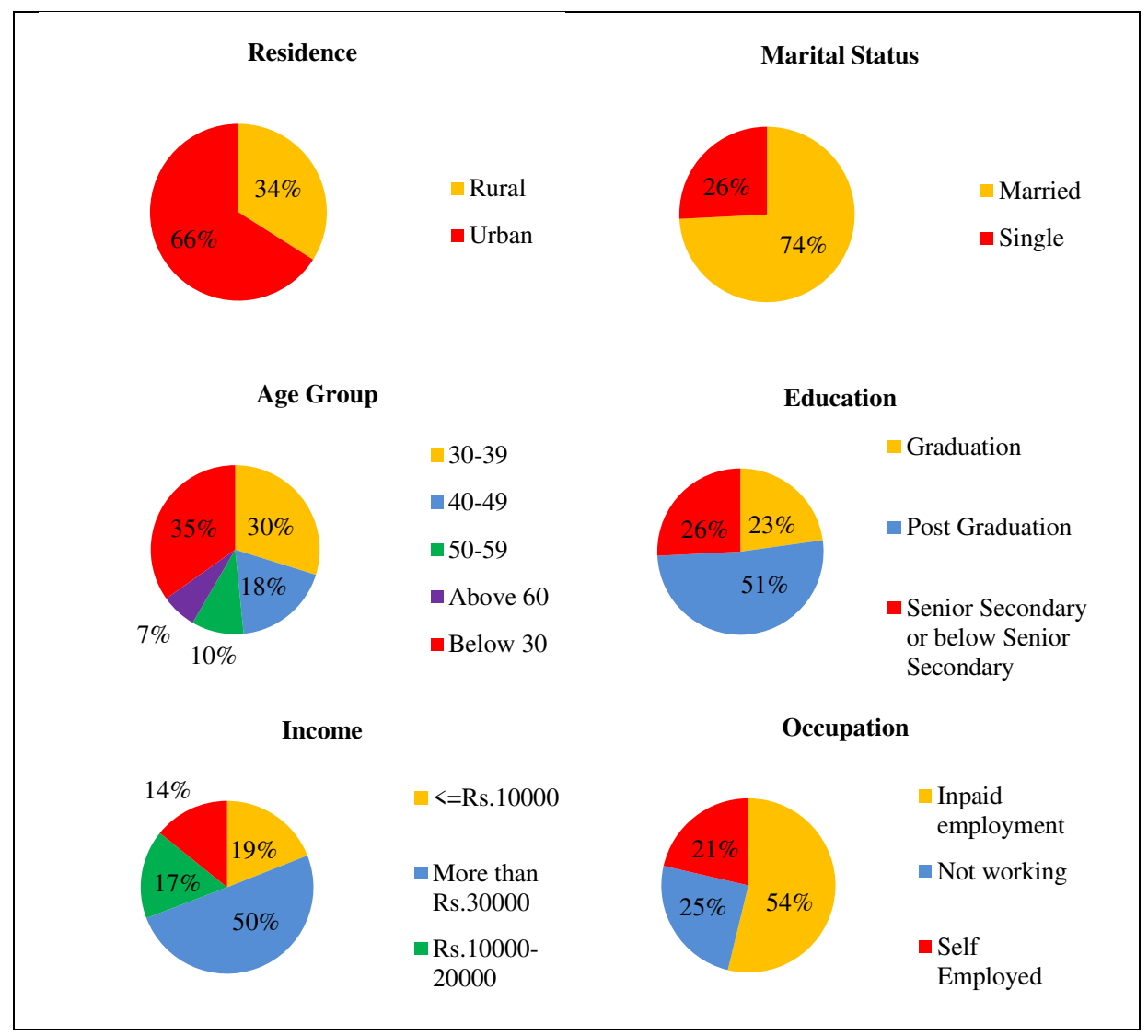

Figure 1. Sample demographic characteristics (continued)

\subsection{Analytical Tools}

Indeed, the nature of the present study is a descriptive one that aims to describe the level of financial literacy of the respondents. An attempt has also been made to explore the factors that affect the level of financial literacy of the respondents. In the study, bar diagrams are used to display the level of financial knowledge, financial attitude, financial behaviour, and financial literacy possessed by the respondents. The average and standard deviation of the scores on financial knowledge, financial attitude, financial behaviour, and financial literacy obtained from the sample respondents are reported for the purpose of analysis.

\subsection{Dummy Variable Regression Analysis}

Existing literature on financial literacy documents various determinants of financial literacy. If studied in isolation, these determinants may yield misleading results. It is useful to undertake multivariate analysis to understand the full picture. This analysis may yield some deeper insights of the association between financial literacy and various demographic factors. We have therefore 
run a dummy variable regression analysis by taking financial literacy and each dimension of financial literacy, i.e., knowledge, attitude, and behaviour, as the dependent variable. In this dummy variable model, the independent variables are gender, domicile, marital status, work situation, age, education, income, and income stability of the respondent.

$$
F L=\alpha+G \beta_{1}+D \beta_{2}+M S \beta_{3}+W S \beta_{4}+A \beta_{5}+E D \beta_{6}+I N C \beta_{7}+I N C S \beta_{8}
$$

where, FL is Financial literacy score of respondent; $G$ is Gender of respondent/0 if participant is a male, 1 otherwise; $\mathrm{D}$ is Domicile of respondent/0 if participant is a urban, 1 otherwise; MS is Marital Status of respondent/0 if participant is married, 1 otherwise; WS is Work Situation of respondent/0 if participant is in paid employment, 1 otherwise; A is Age of respondent/0 if participant is in the age group of more than 40 years, 1 otherwise; ED is Education of respondent/0 if participant possesses a degree of graduation and above, 1 otherwise; INC is Income of respondent/0 if participant's household earnings are more than 20000 p.m., 1 otherwise; INCS is Income Stability of respondent/ 0 if participant's income is stable, 1 otherwise. A similar model is used for analysing the relationship between the demographic factors and financial knowledge, financial behaviour, and financial attitude.

\section{Results and Discussion}

\subsection{Financial Knowledge Analysis}

The financial knowledge of the respondents is judged on the basis of eleven questions incorporated in the survey instrument. It measures the numeracy skills and knowledge of the respondents regarding the basic financial concepts, such as the impact of inflation on prices, on returns and on the standard of living; computation of simple interest and compound interest; risk-return relationship and effect of diversification in risk reduction. All the questions carry equal weight in determining the financial knowledge. The correct answer for each question carries a score of one. Respondents scoring 80 per cent or above were considered as highly knowledgeable and could handle the challenges pertaining to financial matters. Respondents scoring between 60 and 80 per cent were considered as average knowledgeable. Finally, respondents scoring less than 60 per cent were given a low rating in terms of financial knowledge. 


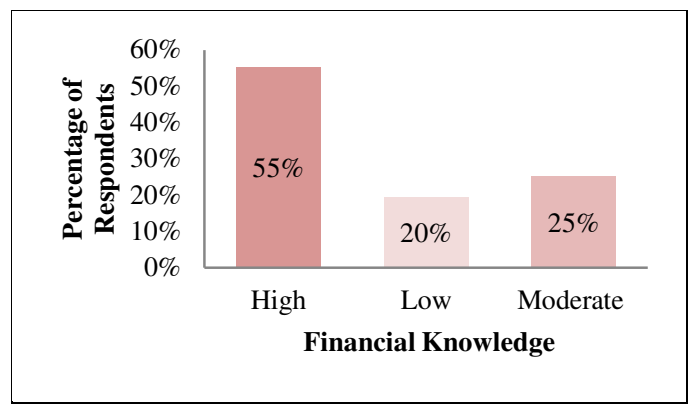

Figure 2. Overall Financial Knowledge

On the basis of the survey of the whole sample, the scores of the respondents on financial knowledge are presented in Figure 2. The results show that 55 per cent of the respondents scored 9 or above for financial knowledge and were placed in the high financial knowledge category. Item wise analysis reveals that the majority of the respondents performed well in simple division and interest calculation and were satisfactorily aware ofrisk-return relationships. However, the survey findings also demonstrated that more than half of the respondents were not able to calculate the impact of time value of money albeit they understood the concept of inflation. More than 40 per cent of the respondents were not able to perform calculations regarding compound interest. Low levels of financial understanding were also found concerning the benefits of diversification.

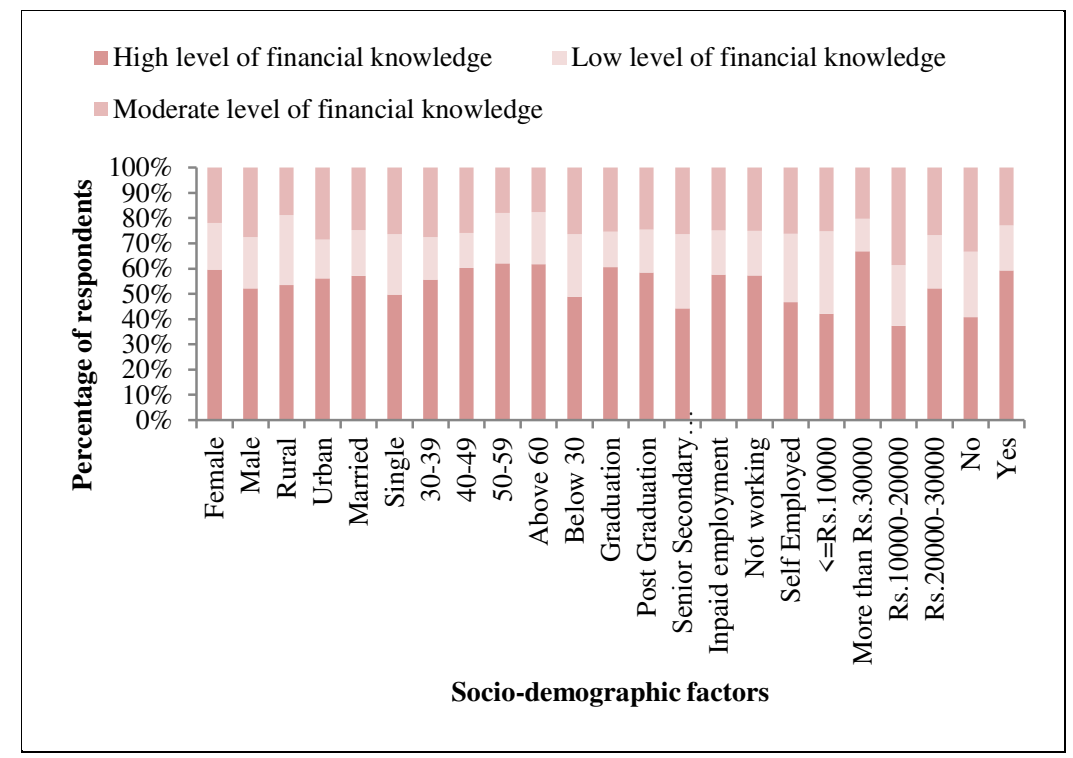

Figure 3. Financial Knowledge by Socio-demographics 
Furthermore, the empirical evidence in Figure 3 indicates that various socio-demographic variables have an influence on the financial knowledge level of the respondents. The research documents variations in the financial knowledge of the respondents on the basis of their residence, marital status, gender, and work situation. The results also depict that education, income, and age have positive influence on the financial knowledge of the respondents as the respondents with ahighereducational degree and high income have higher levels of financial knowledge, and, also, financial knowledge tends to improve with age.

\subsection{Financial Attitude Analysis}

Financial attitude is an important element of financial literacy, as it influences the financial behaviour of people. A total of three items, as recommended by OECD, viz. preference to save, to consume, and preference to make long-term financial plans, were employed to capture the attitude of the respondents towards handling finance. The attitudinal statements sought a response in terms of the degree of agreement or disagreement on a 5-point scale. The score of the respondents was created by adding together their scores for the three attitudinal questions and then dividing by 3 . A score of 4 and above signifies that the respondent has a positive financial attitude, while a neutral financial attitude is represented by score of 3 . A score of 2 or less indicates that the respondent has a negative financial attitude.

The scores for financial attitudes on the basis of all the respondents in the sample are presented in Figure 4. The results exhibit that 43 per cent of the respondents of the whole sample fall in the positive attitude category whereas 30 per cent of the respondents havea negative attitude towards financial planning and a propensity to save, which is a matter of serious concern. Item wise analysis gives important insights into the financial attitude of the respondents. Half of the respondents depict a positive attitude towards savings and long-term financial planning, which, conversely, also suggests that 50 per cent of the respondents live for today and are not bothered about the future. They are not saving today to safeguard their future, and, also, their responses to the individual items suggest that they are not researching their choices when making saving and investment decisions. Moreover, the empirical evidence in Figure 5 displays wide variations in the financial attitude of the respondents on the basis of various demographic factors. Female respondents show a better attitude towards savings and financial decision making than male respondents. The financial attitude of rural respondents is superior to that of urban respondents. Marital status seems to have a significant influence on the financial attitude of the respondents. Perhaps marriage makes the people more conscious about healthy financial future considering the increased responsibilities. 


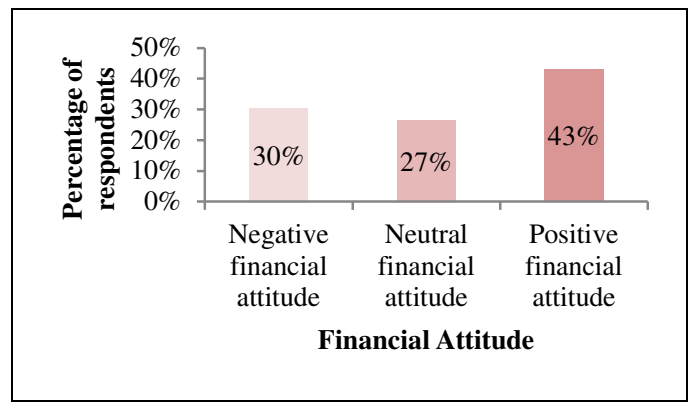

Figure 4. Overall Financial Attitude

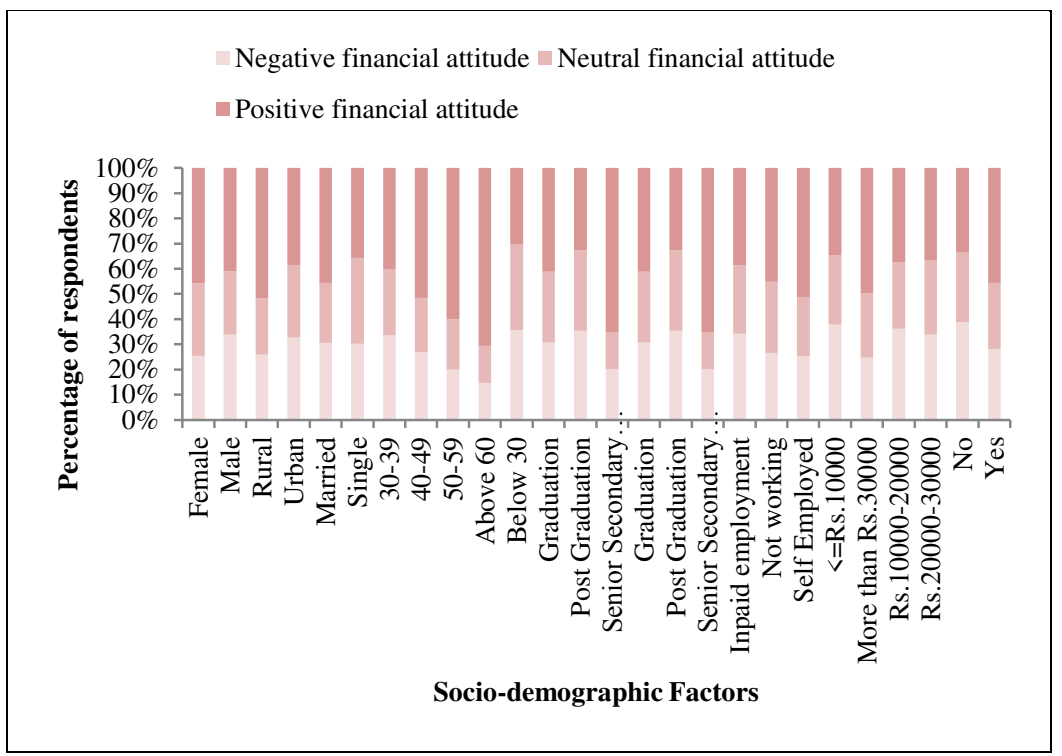

Figure 5. Financial Attitude by Socio-demographics

The survey also indicates that the age and income of the respondents is a significant determinant of the financial attitude of the respondents and a higher positivity is found in the attitude of people falling in the higher age group and high-income class. However, the effect of work status on financial education seems to be insignificant, and the attitude of respondents with low educational degrees is better than others.

\subsection{Financial Behaviour Analysis}

Financial behaviour is an indispensable element of financial literacy and probably the most important one. This is because although people have the knowledge as well as positivity in their attitude towards financial matters, their future financial well-being depends on their behaviour towards utilizing money in their daily lives. The study attempts to show the financial behaviour of the 
respondents by covering the aspects regarding the household budgets, affordability of products and management of expenditure, timely payment of bills, efforts towards achieving financial goals, saving habits, and borrowing tendency.

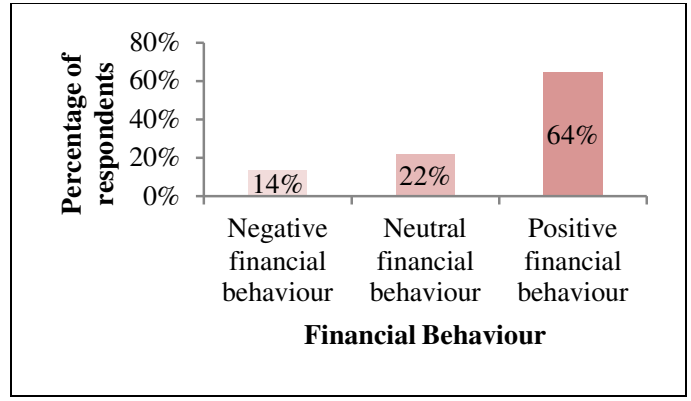

Figure 6. Overall Financial Behaviour

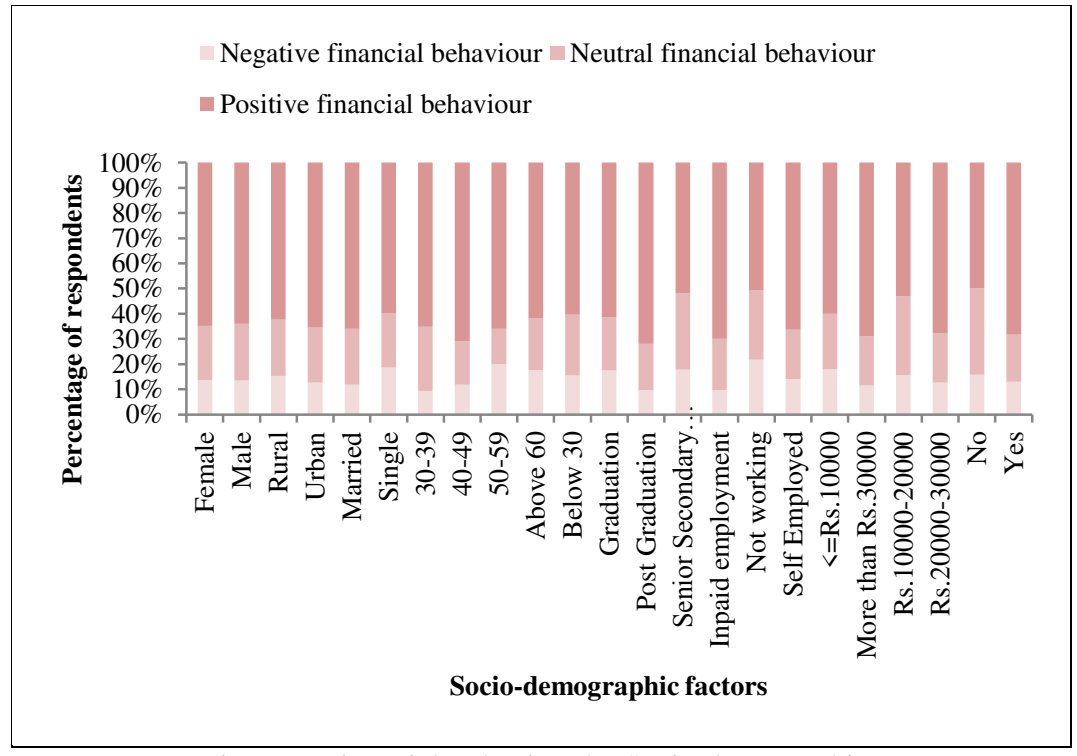

Figure 7. Financial Behaviour by Socio-demographics

The survey instrument includes six items to accumulate information about the respondent's dealings with personal finances. The overall behaviour score is obtained by combining the information on six items. Respondents scoring 5 or more out of 6 are classified as having a positive behaviour towards money and finance. Those scoring 4 are classified as neutral, and less than 4 are considered as having negative financial behaviour.

The scores for financial behaviour on the basis of all the respondents in the sample are presented in Figure 6. The financial behaviour scores of the respondents show that the majority of the respondents depict positive financial 
behaviour while dealing with financial matters. On the basis of the survey findings, 64 per cent of the respondents are categorized in the positive financial behaviour class whereas 14 per centappear in the negative financial behaviour class. Item wise analysis shows that 11 per cent of the respondents are not worried about active saving. The others save, but only 45 per cent park their savings in productive channels. More than 90 per cent of the respondents pay their bills on time and access their affordability before entering into buying transactions. Long-term financial goal setting is reported by a large section of the respondents. All these are good indicators of financial dealings resulting in future financial prosperity.

Furthermore, the empirical evidence in Figure 7 indicates that various socio-demographic variables have an influence on the financial behaviour of the respondents. The research documents that marriage; education, employment, and income appear to be significant variables positively influencing the financial behaviour of the respondents. However, the absence of any significant variation is found in the financial behaviour scores of the respondents on the basis of gender, domicile, and age.

\subsection{Financial Literacy Analysis}

The financial literacy scores of the respondents are obtained by adding their scores for the three dimensions of financial literacy, i.e., financial knowledge, financial attitude, and financial behaviour. The maximum financial literacy score that can be attained by a respondent is 22 ( 11 for financial knowledge 6 for financial behaviour, and 5 for financial attitude). The respondents are categorized in the high financial literacy class on gaining a score of 80 per cent or above, in the moderate financial literacy class for score of 60 to 80 per cent and are considered as less financially literate if they score less than 60 per cent. The financial literacy scoring adopted follows the approach recommended by the OECD and is also followed in some Indian studies (Atkinson and Messy, 2012, Agarwalla et. al, 2012).

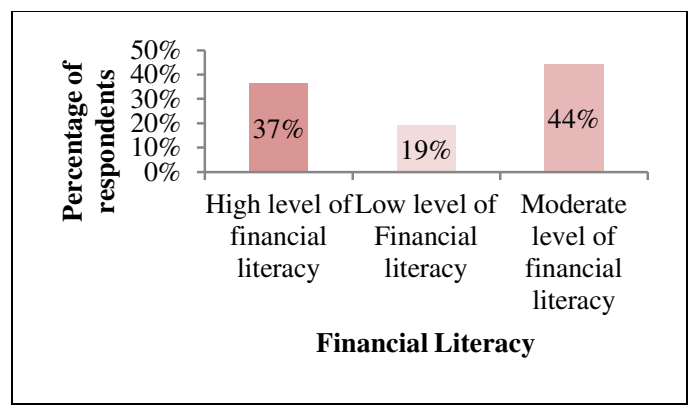

Figure 8. Overall Financial Literacy 
The financial literacy scores of all the respondents in the sample are presented in Figure 8. The results show that 37 per cent of the respondents fall in the high financial literacy category, which suggests that they are well equipped with financial skills and knowledge, and also seem to have a positive attitude or behaviour with regard to financial matters. The other 63 per cent of the respondents are lacking in one or other aspects of financial literacy with 19 per cent of the respondents being ill-equipped in terms of the financial skills essential for their financial well-being as they appear in the category of low financial literacy.

Overall, the results indicate the poor literacy level of the people despite high levels of financial knowledge and financial behaviour. The low level of overall financial literacy is mainly accredited to the poor scores of the respondents for financial attitude. Another factor is the lack of consistency in the results for the three dimensions of financial literacy among the respondents. Just 20 per cent of the respondents scored high for all three dimensions.

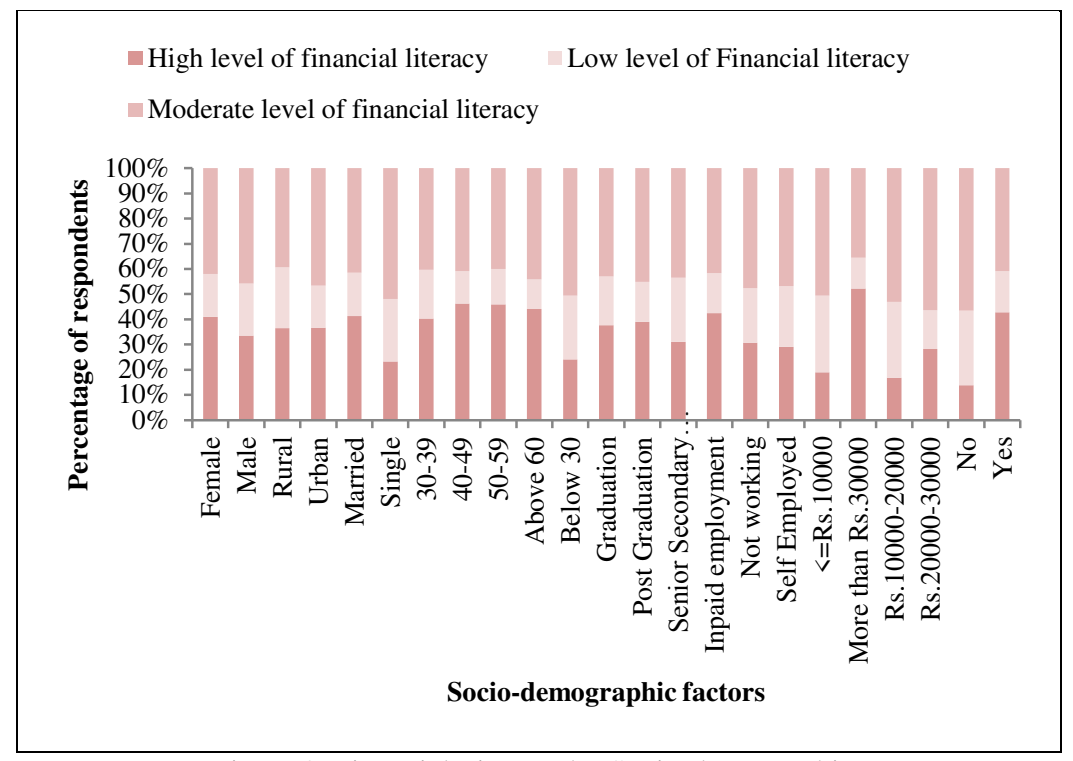

Figure 9. Financial Literacy by Socio-demographics

Figure 9 represents the financial literacy scores of the respondents on the basis of various socio-demographic factors. The financial literacy scores of all the respondents show that the financial literacy level of females is better than that of the male respondents. Furthermore, the married respondents outperform single respondents for all three aspects of financial literacy, i.e. financial knowledge, financial attitude, and financial behaviour. Perhaps increased family responsibilities make the people more conscious of their financial future. They feel the need to improve their financial knowledge and to change their attitude and behaviour towards savings, investment, consumption, and other financial 
matters to secure their financial future. Occupation also emerges as a significant determinant of the financial literacy of the respondents. The results show that the respondents who are in paid employment perform much better than those respondents who are self-employed or not working. The findings also suggest that the level of financial literacy improves with age. Perhaps this is due to the greater exposure of people falling in the high age group, their level of understanding as well as behaviour, which is inclined towards positivity and improving their level of financial literacy. The results based on education level show a positive association between education and financial literacy performance. The findings also document that the people with a higher income possess higher financial knowledge, depict better financial behaviour, and show apositive attitude towards financial matters. Moreover, the evidence based on the sample show that respondents with a stable income outperform the unstable income respondents in all the dimensions of financial literacy, i.e., financial knowledge, financial behaviour, and financial attitude, and score high on financial literacy. However, no significant difference is found in the financial literacy level of the respondents on the basis of their residence.

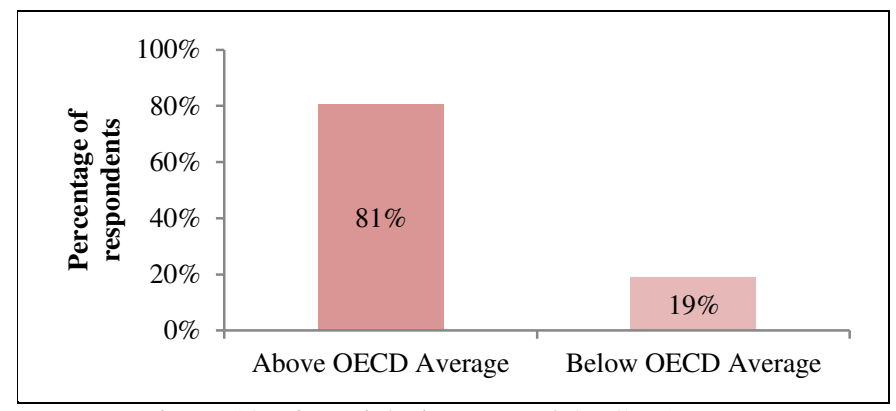

Figure 10. Financial Literacy and OECD Average

The average score of 13.7 observed in the OECD survey (2012) across the set of 13 countries is used as a benchmark to compare Haryana with the rest of the world in Figure 10. The average financial literacy score of the Haryana respondents is about 16.1, which is higher than the average observed in the countries in the OCED survey. Compared to the average score range of 12.4 to 15.1 observed in the countries included in the OECD survey, these results would imply that the average financial literacy level of respondents from Haryana is exceedingly good. Relative to the overall average of the financial literacy score of the OECD survey, the region performs better than several countries, including South Africa, Armenia, Poland, Estonia, and Albania.

\subsection{Multivariate analysis}

While conducting the multivariate analysis, the respondents are bifurcated into graduation and above and below graduation categories on the basis of education; while on the basis of age, they are categorized into two classes: respondents aged 
more than 40 years and respondents aged 40 years and below. Similarly, two categories regarding the income level of the respondents are formed: respondents having an income of less than or equal to Rs. 20000 p.m., and those who have a monthly income of more than Rs. 20000 p.m. Further, respondents are segregated into respondents in paid employment and others on the basis of their occupation.

Table 1. Factors Influencing Respondents' Financial Knowledge

\begin{tabular}{lllll}
\hline Financial Knowledge & Coeff. & Std. Er. & $\boldsymbol{t}$-Stat & $\boldsymbol{p}$-value \\
\hline Intercept & 9.577 & .247 & 38.715 & .000 \\
GENDER & .006 & .212 & .027 & .979 \\
AREA & -.445 & .231 & -1.930 & .054 \\
MARITAL STATUS & -.079 & .265 & -.297 & .767 \\
AGE & -.591 & .244 & -2.421 & .016 \\
EDUCATION & -.624 & .288 & -2.166 & .031 \\
WORK SITUATION & -.281 & .233 & -1.207 & .228 \\
INCOME & -1.155 & .247 & -4.668 & .000 \\
STABILITY & -.419 & .274 & -1.527 & .127 \\
\hline
\end{tabular}

Table 1 shows the regression results of the factors influencing the respondents' financial knowledge. The findings indicate that the average financial knowledge score of the rural respondents is lower by about .445 compared to the average financial knowledge score of the urban respondents, which is a reference category here, holding all other variables constant. The results also show that the respondents aged 40 years and above seem to be more knowledgeable than the younger respondents ceteris paribus, which indicates that the increased experience of dealing with financial transactions improves the financial knowledge of the respondents. Furthermore, education seems to be a significant determinant of financial knowledge as the scores of the respondents who are graduates and above are .624 higher than the undergraduates, which shows that financial knowledge increases with the higher education level of the respondent. The income of the respondents emerges as the most significant factor affecting the financial knowledge of the people, probably because people in the high-income group are more involved in saving, spending, investing, and other financial transactions to dispose of their surplus income.

Table 2. Factors Influencing Respondents' Financial Behaviour

\begin{tabular}{lllll}
\hline Financial Behaviour & Coeff. & Std. Er. & $\boldsymbol{t}$-Stat & $\boldsymbol{p}$-value \\
\hline GENDER & -.008 & .103 & -.075 & .940 \\
AREA & .007 & .112 & .060 & .952 \\
MARITAL STATUS & -.165 & .129 & -1.283 & .200 \\
AGE & -.077 & .119 & -.652 & .515 \\
EDUCATION & -.220 & .140 & -1.569 & .117 \\
WORK SITUATION & -.288 & .113 & -2.548 & .011 \\
INCOME & -.095 & .120 & -.791 & .429 \\
STABILITY & -.309 & .133 & -2.315 & .021 \\
Intercept & 5.046 & .120 & 41.903 & .000 \\
\hline
\end{tabular}


Table 2 shows the regression results of the factors influencing the respondents' financial behaviour. The findings depict that the work situation and stability of the income of the respondent are important factors influencing their financial behaviour. The financial behaviour of the respondents who are in the paid employment class is .288 higher than the respondents who are not working or are self-employed, other things being equal. Perhaps, this may be due to healthy discussions regarding financial aspects with their colleagues and also a concern about savings and investments to minimise tax liabilities. The findings also depict that the financial behaviour of the respondents whose income is stable is better than those having an unstable income. A stable income creates a sense of financial security in the minds of the people, which has a positive bearing on their financial decisions.

Table 3. Factors Influencing Respondents' Financial Attitude

\begin{tabular}{lllll}
\hline Financial Attitude & Coeff. & Std. Er. & $\boldsymbol{t}$-Stat & $\boldsymbol{p}$-value \\
\hline GENDER & .186 & .095 & 1.956 & .051 \\
AREA & .167 & .103 & 1.614 & .107 \\
MARITAL STATUS & .084 & .119 & .706 & .481 \\
AGE & -.392 & .109 & -3.583 & .000 \\
EDUCATION & .697 & .129 & 5.405 & .000 \\
WORK SITUATION & -.001 & .104 & -.012 & .990 \\
INCOME & -.385 & .111 & -3.471 & .001 \\
STABILITY & -.300 & .123 & -2.438 & .015 \\
Intercept & 3.325 & .111 & 29.991 & .000 \\
\hline
\end{tabular}

Table 3 indicates the regression results of factors influencing the respondents' financial attitude. The findings state that among the various sociodemographic factors, age, education, income, and stability of income are the significant factors affecting the financial attitude of the respondents. The results show that the attitude of the respondents who are 40 years and above is more positive concerning the financial aspects than those who are below 40 years of age. Surprisingly, the people who are less educated have a more positive financial attitude than the respondents who are highly educated. The results show that the attitude of the people with a high income is better towards financial matters than the respondents who fall in the low-income group. Further, stability of income emerges as a significant determinant of the financial attitude of the respondents.

Table 4. Factors Influencing Respondents' Financial Literacy

\begin{tabular}{lllll}
\hline Financial Literacy & Coeff. & Std. Er. & $\boldsymbol{t}$-Stat & $\boldsymbol{p}$-value \\
\hline GENDER & .184 & .272 & .676 & .499 \\
AREA & -.272 & .296 & -.918 & .359 \\
MARITAL STATUS & -.160 & .339 & -.472 & .637 \\
AGE & -1.061 & .313 & -3.387 & .001 \\
EDUCATION & -.146 & .369 & -.396 & .692 \\
WORK SITUATION & -.571 & .298 & -1.913 & .056 \\
INCOME & -1.635 & .317 & -5.154 & .000 \\
STABILITY & -1.027 & .352 & -2.922 & .004 \\
Intercept & 17.949 & .317 & 56.579 & .000 \\
\hline
\end{tabular}


Table 4 indicates the regression results of the factors influencing the respondents' financial literacy. The findings demonstrate that men do not score significantly higher than women on the financial literacy scale, ceteris paribus. Likewise, it is curious to note that married and single respondents do equally well in respect of financial matters. There is no significant difference in the financial literacy scores of rural and urban respondents. In addition, one of the vital factors, education, does not record a significant difference in terms of the financial literacy level of the respondents. Although education brings a significant difference in the financial knowledge of the respondents, it is insignificant in terms of changing the attitude and behaviour of the respondents. Thus, the empirical evidence suggests that gender, marital status, education, and domicile remain insignificant factors in explaining the financial literacy of the respondents in the Haryana region even after controlling for other factors.

However, the results demonstrate that the respondents with higher income perform significantly better than the respondents with allow income. They possess higher financial knowledge and have a more sensible financial attitude than their counterparts. Furthermore, it appears from the empirical evidence that the stability of the income of the respondents is an important factor in determining their financial literacy score, as stable income participants score higher in terms of financial attitude and financial behaviour as well as for overall financial literacy than those with an unstable income. The respondents who are in paid employment perform better than others. Age also appears to be a significant factor as people falling in the high age bracket perform better than the people belonging to the low-income group. Overall, the empirical evidence for financial literacy in Haryana indicate that age, work situation, income, and income stability are the significant determinants of the financial literacy of the respondents.

\section{Conclusions}

The empirical evidence emphasizes the rationale for concern. In examining the financial literacy of the people in Haryana, we find that only one-third of the total sample exhibit higher financial literacy. Although the majority of the people possess basic financial knowledge and exhibit positive financial behaviour, 57 per cent of the respondents lack a positive financial attitude. This suggests that the introduction of initiatives on the part of policymakers would be beneficial, as they may be beneficial in changing the attitudes of the respondents. Of particular concern is the relatively large proportion of people who happen to be in the average financial literacy class. However, analysis of the sociodemographics suggests that certain factors may be preventing persons from being more financially literate. In particular, low levels of income, income instability, and low age are associated with lower levels of financial literacy. The present study offers the first ever comprehensive insight into the financial literacy of the Haryana region. The results of this analysis provide evidence from 
which the policymakers can identify the needs and gaps and develop appropriate financial education programmes. In further research, the association between knowledge and specific behaviours, as well as the relationship between attitudes and specific behaviours may also be studied.

\section{References}

Agarwalla, S. K., Barua, S., Jacob, J., \& Varma, J. R. (2012). A survey of financial literacy among students, young employees and the retired in India. Retrieved from http://www.iimahd.ernet.in/

Atkinson, A., \& Messy, F. (2012). Measuring Financial Literacy: results of the OECD/International Network on Financial Education (INFE) (No. 15). Pilot Study. Working Paper.

Australian Securities and Investments Commission. (2011). Financial literacy and behavioural change. Research Report 230, Australian Securities and Investments Commission, Sydney. Retrieved from https://www.moneysmart.gov.au

Boucher, M. R. (2010). Delivering Financial Literacy: Challenges, Strategies and Instruments. Retrieved from https://www.oecd.org/

Chen, H., \& Volpe, R. P. (1998). An analysis of personal financial literacy among college students. Financial Services Review, 7(2), 107-128.

Chakrabarty, K. C. (2010). Keynote address on Furthering Financial Inclusion through Financial Literacy and Credit Counseling. RBI monthly bulletin, (December), 2361-2366. Retrieved from http://rbidocs.rbi.org.in/

Cole, S., Sampson, T., \& Zia, B. (2009, February). Valuing financial literacy training. In Conference on Measurement, Promotion, and Impact of Access to Financial Services, March (pp. 12-13). Retrieved from http://siteresources.worldbank.org/

Cole, S., Sampson, T., \& Zia, B. (2011). Prices or knowledge? What drives demand for financial services in emerging markets? The Journal of Finance, 66(6), 1933-1967.

Demirguc-Kunt, A., Klapper, L., \& Randall, D. (2013). The Global Findex Database, Note no. 8. World Bank, Washington, DC. Retrieved from http://siteresources.worldbank.org/

Grifoni, A., \& Messy, F. A. (2012). Current status of national strategies for financial education: A comparative analysis and relevant practices. $O E C D$ Working Papers on Finance, Insurance and Private Pensions, 16, 1.

Hastings, J. S., \& Mitchell, O. S. (2011). How financial literacy and impatience shape retirement wealth and investment behaviors (No. w16740). National Bureau of Economic Research.

Harris Interactive Inc. (2012). The 2012 consumer financial literacy survey. The National Foundation for Credit Counseling and The Network Branded Prepaid Card Association. Retrieved from https://www.nfcc.org/ 
Klapper, L., \& Panos, G. A. (2011). Financial literacy and retirement planning: the Russian case. Journal of Pension Economics and Finance, 10(4), 599618.

Lusardi, A. (2008). Household saving behavior: The role of financial literacy, information, and financial education programs (No. w13824). National Bureau of Economic Research. Retrieved from http://www.nber.org/

Lusardi, A., \& Mitchell, O. S. (2008). Planning and financial literacy: How do women fare? American Economic Review, 98(2), 413-17.

Lusardi, A., \& Mitchell, O. S. (2017). How Ordinary Consumers Make Complex Economic Decisions: Financial Literacy and Retirement Readiness. Quarterly Journal of Finance, 7(03), 1750008.

Lusardi, A., \& Mitchell, O. S. (2011). Financial literacy around the world: an overview. Journal of Pension Economics \& Finance, 10(4), 497-508.

Lusardi, A., \& Tufano, P. (2015). Debt literacy, financial experiences, and overindebtedness. Journal of Pension Economics and Finance, 14(4), 332368.

MasterCard, (2014). MasterCard index of financial literacy index report 2014 H1. Retrieved from http://www1.mastercard.com/

OECD INFE, (2011). Measuring financial literacy: Core questionnaire in measuring financial literacy: Questionnaire and guidance notes for conducting an internationally comparable survey of financial literacy. Paris: OECD. OECD International Network on Financial Education (INFE). Retrieved from https://www.oecd.org/

OECD INFE, (2012). Supplementary questions: Optional survey questions for the OECD INFE financial literacy core questionnaire. Paris: OECD. OECD International Network on Financial Education (INFE). Retrieved from http://www.oecd.org/

Rutledge, S. L., Annamalai, N., Lester, R., \& Symonds, R. L. (2010). Good practices for consumer protection and financial literacy in Europe and Central Asia: a diagnostic tool. Retrieved from http://siteresources.worldbank.org/

Van Rooij, M., Lusardi, A., \& Alessie, R. (2011). Financial literacy and stock market participation. Journal of Financial Economics, 101(2), 449-472.

VISA (2012). Visa's International Financial Literacy Barometer 2012. Retrieved from http://www.practicalmoneyskills.com/

Kathleen Mumaw CMA, M. B. A. (2010). Mortgage meltdown reveals importance of financial literacy education. Journal of Personal Finance, 9, 61.

Volpe, R.P., \& Mumaw, K. E. (2010). Financial illiteracy and the subprime mortgage crisis. Journal of Business and Accounting, 2(1), 17-31.

Yoshino, N., Morgan, P., \& Wignaraja, G. (2015). Financial education in Asia: Assessment and recommendations. Retrieved from http://www.adb.org/ 